\title{
Acute effects of different orthoses on lower extremity kinetics and kinematics during running; a musculoskeletal simulation analysis
}

\author{
JONATHAN SINCLAIR $^{1 *}$, JANE INGRAM ${ }^{1}$, PAUL JOHN TAYLOR ${ }^{2}$, NACHIAPPAN CHOCKALINGAM ${ }^{3}$ \\ ${ }^{1}$ School of Sport \& Health Sciences, Faculty of Health \& Wellbeing, University of Central Lancashire. \\ ${ }^{2}$ School of Psychology, University of Central Lancashire, \\ ${ }^{3}$ School of Life Science and Education, Staffordshire University.
}

\begin{abstract}
Purpose: The current investigation aimed to examine the effects of different orthotic conditions on the biomechanical mechanisms linked to the aetiology of chronic pathologies using musculoskeletal simulation. Methods: 16 male and 20 females ran over an embedded force plate at $4.0 \mathrm{~m} / \mathrm{s}$, in five different conditions (medial, lateral, no-orthoses, semi-custom and off the shelf). Kinematics of the lower extremities were collected using an eight-camera motion capture system and lower extremity joint loading also explored using a musculoskeletal simulation approach. Differences between orthoses conditions were examined using $2 \times 2$ mixed ANOVA. Results: External instantaneous load rate was significantly reduced in the off the shelf orthoses (male $=1290.60$ and female $=1567.10 \mathrm{~N} / \mathrm{kg} / \mathrm{s}$ ), compared to the medial $(\mathrm{male}=1480.45$ and female $=1767.05 \mathrm{~N} / \mathrm{kg} / \mathrm{s})$ and semi-custom (male $=1552.99$ and female $=1704.37 \mathrm{~N} / \mathrm{kg} / \mathrm{s})$ conditions. In addition, peak patellofemoral stress was significantly lower in the off the shelf orthoses (male $=68.55$ and female $=94.91 \mathrm{KPa} / \mathrm{kg}$ ) compared to the lateral condition (male $=70.49$ and female $=103.22 \mathrm{KPa} / \mathrm{kg}$ ). Finally, peak eversion angles were significantly attenuated in the medial orthoses $(\mathrm{male}=-6.61$ and female $=-7.72 \mathrm{deg})$ compared to the lateral (male $=-9.61$ and female $=-10.32 \mathrm{deg})$, no-orthoses $(\mathrm{male}=-8.22$ and female $=-10.10 \mathrm{deg})$, semi-custom $($ male $=-8.25$ and female $=-9.49 \mathrm{deg})$ and off the shelf $($ male $=-7.54$ and female $=-8.85 \mathrm{deg})$ conditions. Conclusions: The current investigation shows that different orthotic devices/ configurations may provide distinct benefits in terms of their effectiveness in attenuating the biomechanical parameters linked to the aetiology of chronic running injuries.
\end{abstract}

Key words: running, orthoses, biomechanics, pathology

\section{Introduction}

Regular engagement with distance running has long been associated with a plethora of physiological and psychological advantages. However, due to its cyclical nature, distance running is also associated with an extremely high incidence of chronic pathologies; with an occurrence rate of up to $70 \%$ [33]. Specifically, patellofemoral pain, tibial stress fractures, medial tibial stress syndrome, Achilles tendinopathy and pain secondary to hip and knee osteoarthritis are common complaints reported by runners [20], [32]-[34].

Patellofemoral pain is the most common chronic pathology in runners [33]. Elevated patellofemoral joint stress is the biomechanical parameter most strongly linked to the aetiology of patellofemoral pain syndrome [9]. Patellofemoral pain symptoms persist for many years, and, importantly, $>45 \%$ of individuals with patellofemoral pain later present with osteoarthritis at this joint [15]. In addition, degenerative tibiofemoral joint pathologies account for up to $16.8 \%$ of knee pathologies in runners [33]. The medial tibiofemoral compartment is considered significantly more prone to degeneration than the lateral aspect [36], and the biomechanical parameter most strongly associated with the initiation of knee osteoarthritis is the magnitude of the compressive load experienced at the joint [22].

Furthermore, Achilles tendinopathy is also a common chronic pathology in runners, responsible for up

\footnotetext{
* Corresponding author: Jonathan Sinclair, University of Central Lancashire, Darwin Building 217, PR1 2HE, Preston, United Kingdom. Phone: 01772 253585, e-mail: jksinclair@uclan.ac.uk

Received: June 13rd, 2019

Accepted for publication: September 19th, 2019
} 
to $15 \%$ of all reported injuries [34]. Although regarded as the strongest tendon in the body, the Achilles tendon is subjected to forces up to 7 times bodyweight during running [2]. Excessive cyclic stresses borne the tendon are regarded as the main biomechanical stimulus for the initiation of Achilles tendinopathy [1]. Additionally, medial tibial stress syndrome is similarly a frequently reported chronic running injury cause of running-related injury, accounting for $\geq 13.6 \%$ of all injuries and causing discomfort at the posteriomedial aspect of the tibia [20]. The biomechanical mechanisms most prominently linked to the aetiology of medial tibial stress syndrome are the magnitudes of plantarflexion range of motion and hip external rotation range of motion [12]. Finally, tibial stress fractures are also a serious chronic musculoskeletal injury in runners, representing between $0.5-21.1 \%$ of all pathologies [32]. The distal-anterior aspect of the tibia is the most frequent location for stress fractures, and retrospective analyses indicate that excessive tibial accelerations/ vertical rates of loading are the biomechanical mechanisms predominantly responsible for the development of stress fractures [35].

Taking the rate of chronic pathologies in runners into account, conservative prophylactic strategies are a key priority for clinical analyses. Foot orthoses are commonly utilized for the prevention/ treatment of chronic running injuries, and a range of foot orthoses are available, typically classified either as off-the-shelf or custom devices. Off-the-shelf devices are prefabricated by the manufacturer and the design/ fit of the devices are predetermined. Custom orthoses conversely enable the shape, design and fit of the orthotic to be specifically tailored to the individual. However, custom orthoses are typically very expensive and can take several weeks to manufacture. Therefore, orthotic manufacturers have introduced semi-custom devices which can be heat moulded to fit each runner's feet more readily, but at a much lower cost in relation to fully customized devices. In addition to traditional foot orthoses, wedged orthoses that are built up along either the medial or lateral edges have also become common in recent years (Aminian et al. 2014). Wedged devices focus more specifically on modifying the alignment of the lower extremities rather than providing cushioning [30]. Previous clinical analyses have shown that orthoses may be effective in reducing the incidence of lower limb injuries. Bonanno et al. [5] showed that prefabricated foot orthoses mediated a 34\% reduction in the risk of developing medial tibial stress syndrome, patellofemoral pain, Achilles tendinopathy or plantar fasciitis in Australian navy recruits. Similarly, Franklyn-Miller et al. [10] showed that military officer train- ees who received custom orthoses had a significantly reduced absolute injury risk ( 1 injury per 4666 hours of training), compared to a control group (1 injury per 1600 hours of training). Finally, Sinclair et al., [31] showed that semi-custom foot orthoses mediated significant reductions in patellofemoral pain symptoms in runners from both the strong and weak and tight subgroups of patellofemoral pain patients.

The effects of foot orthoses on lower extremity kinetics and kinematics during running has been explored previously in biomechanical literature. Laughton et al. [18] and Mündermann et al. [23] found that off the shelf orthoses significantly reduced tibial accelerations and loading rates during running, although Butler et al. [6] showed that custom devices had no effect on impact loading parameters. Sinclair et al. [28] showed that medial orthoses reduced peak eversion and tibial internal rotation, yet Almonroeder et al. [2] showed using off-the-shelf devices that eversion/ tibial internal rotation parameters were not significantly affected. In addition, Sinclair et al. [29] also showed that off the shelf orthoses significantly reduced peak Achilles tendon force, but Sinclair et al. [26] revealed that semi-custom orthoses had no effect on Achilles tendon kinetics in female runners. Finally, Sinclair [29] showed that both medial and lateral orthoses significantly increased patellofemoral kinetics during the stance phase. Foot orthoses are utilized as blanket term for a range of distinct devices that may include off the shelf, custom orthoses, semi-custom devices, heel-lifts, lateral/medial wedges and flat insoles. To date, there has yet to be a published investigation of the biomechanical effects of off the shelf, semi-custom, and medial/ lateral orthoses on lower extremity kinetics and kinematics linked to the aetiology of chronic running injuries.

In addition, previous analyses examining the biomechanical effects of foot orthoses, have utilized joint torque-driven musculoskeletal modelling approaches to quantify the loads experienced by the lower extremities. However, as skeletal muscle forces are the main contributors to lower extremity joint loading, musculoskeletal modelling methodologies may not necessarily characterize localized joint kinetics [14]. Therefore, more contemporary musculoskeletal simulation-based approaches, which enable skeletal muscle forces to be simulated during human movement, and employed as inputs to calculate lower extremity joint reaction forces may be more appropriate [7]. Such approaches have not yet been adopted to explore biomechanical differences between different orthoses during running.

Therefore, the aim of the current investigation was to examine the effects of the aforementioned orthotic 
conditions on the biomechanical mechanisms linked to the aetiology of chronic pathologies, using a musculoskeletal simulation-based analysis. An investigation of this nature may provide insight into the potential efficacy of different foot orthoses for the prevention of chronic running pathologies.

\section{Materials and methods}

\section{Participants}

Thirty-six participants (16 male and 20 female) volunteered to take part in the current investigation. The mean and standard deviation characteristics of the participants were (male: age $28.69 \pm 6.06$ years, height $177.75 \pm 5.02 \mathrm{~cm}$, body mass $76.58 \pm 8.68 \mathrm{~kg}$ and foot posture index $=3.00 \pm 1.63$ and female: age 32.25 \pm 7.36 years, height $161.29 \pm 5.61 \mathrm{~cm}$, body mass $65.51 \pm 7.34 \mathrm{~kg}$ and and foot posture index $=3.90$ \pm 2.43 ). All were identified as recreational runners who trained 3 times a week, completing a minimum of $35 \mathrm{~km}$. Participants were all injury-free at the time of data collection and had not undergone lower extremity musculoskeletal surgery. The procedure applied for this investigation was approved by the University of Central Lancashire, Science, Technology, Engineering and Mathematics, ethical committee (Ref: 874) and all participants provided written informed consent.

\section{Orthoses}

Five experimental conditions were examined in this investigation (lateral, medial, semi-custom, off-the-shelf and no orthotic). For the medial and lateral orthoses, commercially available full-length orthoses (Slimflex Simple, High Density, Full Length, Algeos UK) were examined. The orthoses were able to be modified to either a $5^{\circ}$ varus or valgus configuration which in two separate components spanned the full length of the device. The orthoses were made from ethylene-vinyl acetate with a shore A rating of 65 and had a heel thickness of $11 \mathrm{~mm}$ including the additional wedge. The semi-custom insoles (Sole Control, Sole, Milton Keynes, UK), were made from ethylene-vinyl acetate with a shore A 30 hardness rating and a heel thickness of $6 \mathrm{~mm}$. To mould the insoles, they were placed into a pre-heated oven $\left(90^{\circ} \mathrm{C}\right)$ for a duration of two minutes. The heated insoles were then placed inside the shoes and participants were asked to stand upright without moving for two minutes to enable the process of moulding the insoles to the longitudinal arch profile of each participant, in accordance with manufacturer instructions. The off-the-shelf orthoses (Sorbothane, shock stopper sorbo Pro, Nottinghamshire, UK) were made from a custom polyurethane polymer and had a heel thickness of $6 \mathrm{~mm}$ and a shore A hardness rating of 10. To ensure consistency, each participant wore the same footwear (Asics, Patriot 6). The experimental footwear had a mean mass of $0.265 \mathrm{~kg}$, heel thickness of $22 \mathrm{~mm}$ and heel drop of $10 \mathrm{~mm}$. The order that participants ran in each orthotic condition was counterbalanced.

\section{Procedure}

Participants ran across a $20 \mathrm{~m}$ biomechanics laboratory surface (MondoSport Ramflex, Mondo, Italy) at $4.0 \mathrm{~m} / \mathrm{s}( \pm 5 \%)$, striking an embedded piezoelectric force platform (Kistler, Kistler Instruments, Ltd., Alton, Hampshire), which sampled at $1000 \mathrm{~Hz}$, with their right (dominant) foot. Running velocity was monitored using infrared timing gates (Newtest, Oy Koulukatu, Finland). The stance phase was delineated as the duration over which $20 \mathrm{~N}$ or greater of vertical force was applied to the force platform. Runners completed five successful trials in each of the five different orthotic conditions. A successful trial was defined as one within the specified velocity range, where all tracking clusters were in view of the cameras, the foot made full contact with the force plate and there was no evidence of gait modifications due to the experimental conditions. The order that participants ran in each condition was counterbalanced, by providing each orthotic with a letter from A-E and block counterbalancing the order in which each was presented to each participant. Kinematics and ground reaction forces data were synchronously collected. Kinematic data was captured at $250 \mathrm{~Hz}$ via an eight-camera motion analysis system (Qualisys Medical AB, Goteburg, Sweden). Dynamic calibration of the motion capture system was performed before each data collection session.

After being tested in each orthotic condition, participants were asked to provide their rating of the comfort of each one. The comfort measurement procedure consisted of a $150 \mathrm{~mm}$ visual analogue scale with the extreme left side being indicative of "not comfortable at all" and the extreme right of the scale labelled as "most comfortable condition imaginable" [23]. Upon conclusion of the data collection, participants were also asked to subjectively indicate which orthotic condition that they preferred.

To define the anatomical frames of the thorax, pelvis, thighs, shanks and feet retroreflective markers were placed at the C7, T12 and xiphoid process landmarks and also positioned bilaterally onto the acromion process, iliac crest, anterior superior iliac spine (ASIS), posterior super iliac spine (PSIS), medial and 
lateral malleoli, medial and lateral femoral epicondyles, greater trochanter, calcaneus, first metatarsal and fifth metatarsal. Carbon-fibre tracking clusters comprising of four non-linear retroreflective markers were positioned onto the thigh and shank segments. In addition to those, the foot segments were tracked via the calcaneus, first metatarsal and fifth metatarsal, the pelvic segment was tracked using the PSIS and ASIS markers and the thorax segment was tracked using the T12, C7 and xiphoid markers. Static calibration trials were obtained with the participant in the anatomical position in order for the positions of the anatomical markers to be referenced in relation to the tracking clusters/markers. A static trial was conducted with the participant in the anatomical position in order for the anatomical positions to be referenced in relation to the tracking markers, following which those not required for dynamic data were removed.

To measure axially directed accelerations at the tibia, an accelerometer (Biometrics ACL 300, Gwent United Kingdom) sampling at $1000 \mathrm{~Hz}$, was used. The device was mounted onto a piece of lightweight carbon-fibre material using the protocol outlined by Sinclair et al. [24]. The accelerometer was attached securely to the distal anterio-medial aspect of the tibia in alignment with its longitudinal axis, $0.08 \mathrm{~m}$ above the medial malleolus. Strong non-stretch adhesive tape was placed over the device and leg to avoid overestimating the acceleration due to tissue artefact.

The Achilles tendon of each participant's examined (right) side was inspected using ultrasound imaging (SonoScope A6, Sonomed, China). Each participant laid face downwards on a physiotherapy table with their ankle joint in a neutral position. A $46 \mathrm{~mm} 5-11 \mathrm{MHz}$ linear ultrasound probe (model L745) was placed perpendicularly to the Achilles tendon, between the medial and lateral malleoli [21]. The medial-lateral and anteriorposterior dimensions were recorded, and the crosssectional area was calculated using the associated formula for an oval, i.e., Anterior-posterior * medial-lateral $* \pi / 4$. Three images were obtained from each participant and the mean of these recordings was calculated.

\section{Processing}

Dynamic trials were digitized using Qualisys Track Manager in order to identify anatomical and tracking markers, then exported as C3D files to Visual 3D (C-Motion, Germantown, MD, USA). All data were normalized to $100 \%$ of the stance phase, then processed trials were averaged within subjects for statistical analysis. Ground reaction force and kinematic data were smoothed using cut-off frequencies of 50 and $12 \mathrm{~Hz}$ with a low-pass Butterworth 4th order zero lag filter
[29]. All net force parameters throughout were normalized by dividing by body mass $[\mathrm{N} / \mathrm{kg}]$. Threedimensional kinematic measures, extracted for statistical analysis using Visual 3D from the hip, knee, ankle, were 1) angle at footstrike, 2) peak angle during the stance phase and 3) angular range of motion (ROM) from footstrike to peak angle. In addition, tibial internal rotation kinematics were also calculated in accordance with Eslami et al., [8]. From the force platform, the external instantaneous loading rate $[\mathrm{N} / \mathrm{kg} / \mathrm{s}]$ was calculated by obtaining the peak increase in force between adjacent data points. In addition, the tibial acceleration signal was filtered using a $60 \mathrm{~Hz}$ Butterworth zero lag 4th order low pass filter [24], and the peak tibial acceleration $[\mathrm{g}]$ was extracted as the highest positive acceleration peak during the stance phase.

Data during the stance phase were exported from Visual 3D into OpenSim 3.3 software (Simtk.org). A validated musculoskeletal model with 12 segments, 19 degrees of freedom and 92 musculotendon actuators [19] was used to estimate extremity joint forces. The model was scaled for each participant to account for the anthropometrics of each athlete. As muscle forces are the main determinant of joint compressive forces [14], muscle kinetics were quantified using static optimization. Peak compressive patellofemoral, medial/lateral tibiofemoral, ankle and hip joint forces were calculated via the joint reaction analyses function using the muscle forces generated from the static optimization process. Furthermore, peak patellofemoral stress $[\mathrm{KPa} / \mathrm{kg}]$ was quantified by dividing the patellofemoral force by the contact area. Patellofemoral contact areas were obtained by fitting a polynomial curve to the sex specific data of Besier et al., [4], who estimated patellofemoral contact areas as a function of the knee flexion angle using MRI.

Achilles tendon forces were estimated in accordance with the protocol of Almonroeder et al., [2], by summing the muscle forces of the medial gastrocnemius, lateral, gastrocnemius, and soleus muscles. In addition, Achilles tendon stress was estimated by dividing the Achilles tendon forces by the cross-sectional area of the tendon measured from the ultrasound images. Peak Achilles tendon force $[\mathrm{N} / \mathrm{kg}]$ and stress $[\mathrm{KPa} / \mathrm{kg}]$ were extracted for statistical analysis.

In addition, patellofemoral, medial/lateral tibiofemoral, ankle, hip and Achilles tendon instantaneous load rates $[\mathrm{N} / \mathrm{kg} / \mathrm{s}$ and $\mathrm{KPa} / \mathrm{kg} / \mathrm{s}]$ were also extracted by obtaining the peak increase in force/stress between adjacent data points. Finally, the integral of the hip, tibiofemoral, ankle, patellofemoral and Achilles tendon forces $[\mathrm{N} / \mathrm{kg} \cdot \mathrm{s}]$ and stresses $[\mathrm{KPa} / \mathrm{kg} \cdot \mathrm{s}]$ during the stance phase were calculated using a trapezoidal function. 


\section{Statistical analyses}

Descriptive statistics of means and standard deviations were obtained for each outcome measure and for each orthotic condition. Shapiro-Wilk tests were used to screen the data for normality. Differences in biomechanical parameters were examined using 5 (ORTHOTIC) $\times 2$ (GENDER) mixed ANOVA's and differences in comfort ratings were examined using 4 (ORTHOTIC) $\times 2$ (GENDER) mixed ANOVA's. Statistical significance was accepted at the $P \leq 0.05$ level and effect sizes for all significant findings were calculated using partial $\operatorname{Eta}^{2}\left(p \eta^{2}\right)$. In the event of a significant main effect, pairwise comparisons were performed. Finally, a chi-squared $\left(\chi^{2}\right)$ test was utilised to test the assumption that an equal number of participants would subjectively favour each of the orthotic conditions. All statistical actions were conducted using SPSS v25.0 (SPSS, Inc., Chicago, USA).

\section{Results}

\section{Joint kinetics}

\section{Medial tibiofemoral joint}

At the medial aspect of the tibiofemoral joint, there was a main effect of GENDER $\left(P<0.05, p \eta^{2}=0.34\right)$ for the peak medial tibiofemoral force, with peak

Table 1. Hip and knee joint kinetics (Mean and SD) for each orthotic condition

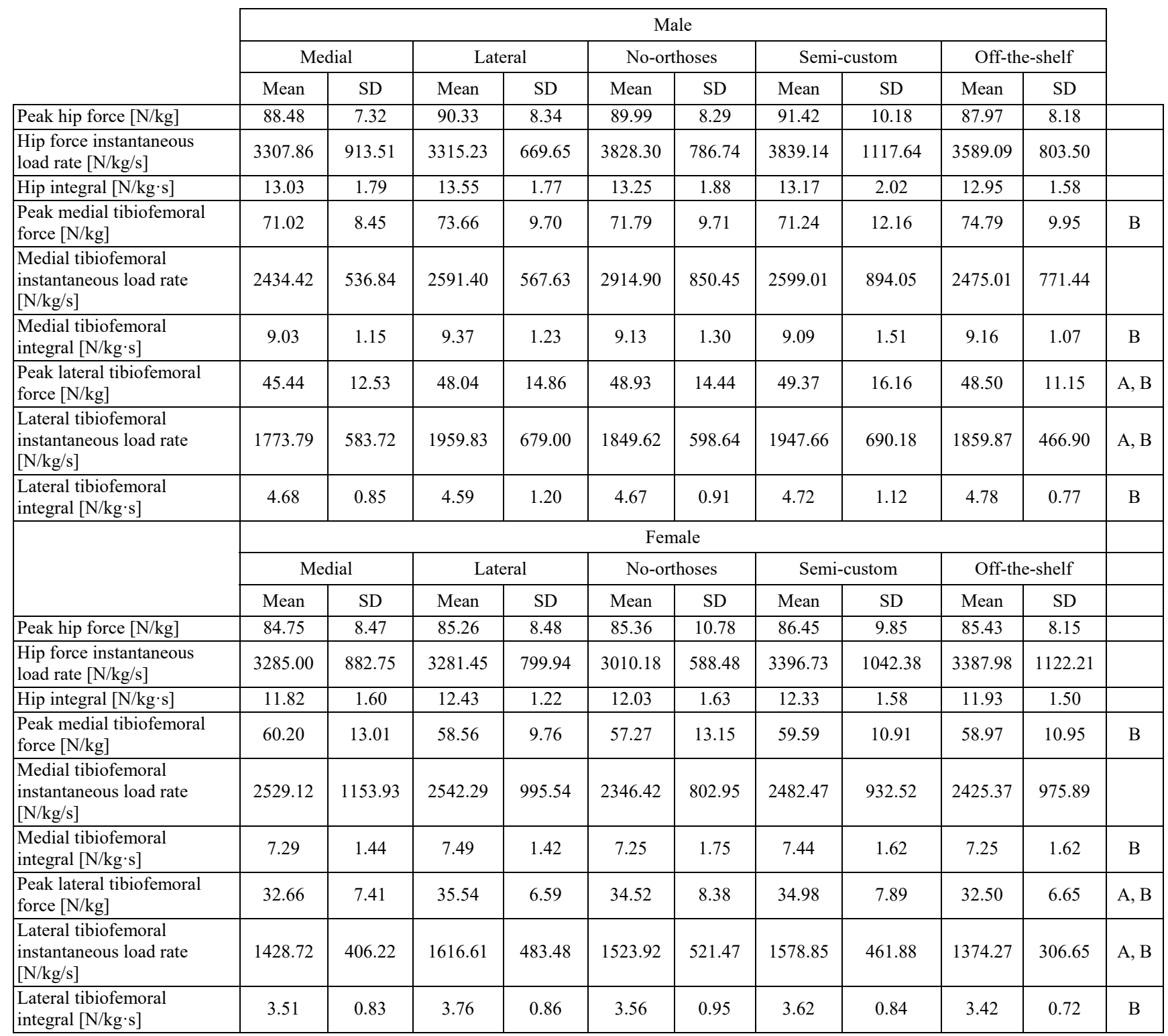

Key: A = main effect of ORTHOSES, B = main effect of GENDER. 
force being greater in male runners. In addition, there was a main effect of GENDER $\left(P<0.05, p \eta^{2}=0.33\right)$ for the medial tibiofemoral integral, with the medial tibiofemoral integral being greater in males.

\section{Lateral tibiofemoral joint}

At the lateral aspect of the tibiofemoral joint, there was a main effect of GENDER $\left(P<0.05, p \eta^{2}=0.38\right)$ for the peak lateral tibiofemoral force, with peak force being greater in male runners. In addition, there was a main effect of ORTHOTIC $\left(P<0.05, p \eta^{2}=0.38\right)$. Post-hoc pairwise comparisons showed that the peak lateral tibiofemoral force was significantly greater in the lateral $(P=0.023)$ condition, compared to the medial orthoses. In addition, there was a main effect of GENDER $\left(P<0.05, p \eta^{2}=0.16\right)$ for the lateral tibiofemoral instantaneous loading rate, with this parameter being greater in male runners. In addition,

Table 2. Patellofemoral and joint kinetics (Mean and SD) for each orthotic condition

\begin{tabular}{|c|c|c|c|c|c|c|c|c|c|c|c|}
\hline & & & & & & & & & & & \\
\hline & \multicolumn{10}{|c|}{ Male } & \\
\hline & \multicolumn{2}{|c|}{ Medial } & \multicolumn{2}{|c|}{ Lateral } & \multicolumn{2}{|c|}{ No-orthoses } & \multicolumn{2}{|c|}{ Semi-custom } & \multicolumn{2}{|c|}{ Off-the-shelf } & \\
\hline & Mean & SD & Mean & $\mathrm{SD}$ & Mean & $\mathrm{SD}$ & Mean & SD & Mean & $\mathrm{SD}$ & \\
\hline Peak ankle force $[\mathrm{N} / \mathrm{kg}]$ & 115.69 & 22.41 & 118.63 & 15.40 & 117.87 & 19.59 & 121.14 & 21.30 & 120.16 & 15.85 & $\mathrm{~B}$ \\
\hline $\begin{array}{l}\text { Ankle force instantaneous } \\
\text { load rate }[\mathrm{N} / \mathrm{kg} / \mathrm{s}]\end{array}$ & 3129.58 & 1059.63 & 3218.30 & 649.58 & 3334.58 & 941.19 & 3227.41 & 509.45 & 3148.57 & 656.10 & \\
\hline Ankle integral $[\mathrm{N} / \mathrm{kg} \cdot \mathrm{s}]$ & 13.48 & 2.61 & 13.95 & 1.65 & 13.75 & 2.35 & 14.39 & 2.67 & 14.08 & 2.13 & $\mathrm{~B}$ \\
\hline $\begin{array}{l}\text { Peak patellofemoral } \\
\text { force }[\mathrm{N} / \mathrm{kg}]\end{array}$ & 40.26 & 14.78 & 40.54 & 16.90 & 39.00 & 13.16 & 40.01 & 14.42 & 39.14 & 13.50 & A \\
\hline $\begin{array}{l}\text { Peak patellofemoral } \\
\text { stress }[\mathrm{KPa} / \mathrm{kg}]\end{array}$ & 70.56 & 22.11 & 70.49 & 25.69 & 68.92 & 19.93 & 70.15 & 21.80 & 68.55 & 20.63 & A, B \\
\hline $\begin{array}{l}\text { Patellofemoral force } \\
\text { instantaneous load rate } \\
{[\mathrm{N} / \mathrm{kg} / \mathrm{s}]}\end{array}$ & 1272.87 & 339.23 & 1274.20 & 339.02 & 1306.85 & 380.22 & 1310.70 & 336.69 & 1217.09 & 268.24 & \\
\hline $\begin{array}{l}\text { Patellofemoral stress } \\
\text { instantaneous load rate } \\
{[\mathrm{KPa} / \mathrm{kg} / \mathrm{s}]}\end{array}$ & 2466.63 & 585.35 & 2477.26 & 429.23 & 2782.31 & 877.60 & 2721.66 & 588.61 & 2506.96 & 602.10 & B \\
\hline $\begin{array}{l}\text { Patellofemoral force } \\
\text { integral }[\mathrm{N} / \mathrm{kg} \cdot \mathrm{s}]\end{array}$ & 3.10 & 1.31 & 3.33 & 1.73 & 2.95 & 1.13 & 3.03 & 1.35 & 3.13 & 1.28 & $\mathrm{~A}$ \\
\hline \multirow[t]{4}{*}{$\begin{array}{l}\text { Patellofemoral stress } \\
\text { integral }[\mathrm{KPa} / \mathrm{kg} \cdot \mathrm{s}]\end{array}$} & 5.60 & 2.11 & 5.90 & 2.83 & 5.40 & 1.89 & 5.50 & 2.22 & 5.60 & 2.08 & A, B \\
\hline & \multicolumn{10}{|c|}{ Female } & \\
\hline & \multicolumn{2}{|c|}{ Medial } & \multicolumn{2}{|c|}{ Lateral } & \multicolumn{2}{|c|}{ No-orthoses } & \multicolumn{2}{|c|}{ Semi-custom } & \multicolumn{2}{|c|}{ Off-the-shelf } & \\
\hline & Mean & SD & Mean & SD & Mean & SD & Mean & SD & Mean & SD & \\
\hline Peak ankle force $[\mathrm{N} / \mathrm{kg}]$ & 96.42 & 16.52 & 98.71 & 12.73 & 98.83 & 16.37 & 97.52 & 17.63 & 95.96 & 14.61 & $\mathrm{~B}$ \\
\hline $\begin{array}{l}\text { Ankle force instantaneous } \\
\text { load rate }[\mathrm{N} / \mathrm{kg} / \mathrm{s}]\end{array}$ & 3013.14 & 736.42 & 3020.20 & 631.00 & 2817.86 & 679.30 & 3028.02 & 681.18 & 2960.76 & 789.04 & \\
\hline Ankle integral $[\mathrm{N} / \mathrm{kg} \cdot \mathrm{s}]$ & 11.72 & 2.05 & 12.05 & 1.84 & 11.73 & 2.25 & 11.83 & 2.30 & 11.62 & 1.87 & $\mathrm{~B}$ \\
\hline $\begin{array}{l}\text { Peak patellofemoral } \\
\text { force }[\mathrm{N} / \mathrm{kg}]\end{array}$ & 46.86 & 14.56 & 48.56 & 12.39 & 44.59 & 10.83 & 49.01 & 16.86 & 44.39 & 11.53 & A \\
\hline $\begin{array}{l}\text { Peak patellofemoral } \\
\text { stress }[\mathrm{KPa} / \mathrm{kg}]\end{array}$ & 100.28 & 24.13 & 103.22 & 20.69 & 96.57 & 17.88 & 104.41 & 30.19 & 94.91 & 18.83 & A, B \\
\hline $\begin{array}{l}\text { Patellofemoral force } \\
\text { instantaneous load rate } \\
{[\mathrm{N} / \mathrm{kg} / \mathrm{s}]}\end{array}$ & 1473.54 & 521.20 & 1423.69 & 409.31 & 1388.64 & 517.25 & 1390.18 & 354.61 & 1367.60 & 486.44 & \\
\hline $\begin{array}{l}\text { Patellofemoral stress } \\
\text { instantaneous load rate } \\
{[\mathrm{KPa} / \mathrm{kg} / \mathrm{s}]}\end{array}$ & 3785.04 & 1398.42 & 3633.07 & 1118.76 & 3658.16 & 1305.26 & 3667.80 & 949.96 & 3584.23 & 1450.64 & B \\
\hline $\begin{array}{l}\text { Patellofemoral force } \\
\text { integral }[\mathrm{N} / \mathrm{kg} \cdot \mathrm{s}]\end{array}$ & 4.01 & 1.43 & 4.15 & 1.20 & 3.89 & 1.33 & 4.14 & 1.74 & 3.76 & 1.31 & A \\
\hline $\begin{array}{l}\text { Patellofemoral stress } \\
\text { integral }[\mathrm{KPa} / \mathrm{kg} \cdot \mathrm{s}]\end{array}$ & 9.00 & 2.55 & 9.30 & 2.03 & 8.80 & 2.28 & 9.30 & 3.25 & 8.50 & 2.32 & A, B \\
\hline
\end{tabular}

Key: A = main effect of ORTHOSES, B = main effect of GENDER. 
there was a main effect of ORTHOTIC $(P<0.05$, $\left.p \eta^{2}=0.10\right)$. Post-hoc pairwise comparisons showed that the lateral tibiofemoral instantaneous loading rate was significantly greater in the lateral $(P=0.025)$ condition, compared to the medial orthoses. Finally, there was a main effect of GENDER $\left(P<0.05, p \eta^{2}=0.35\right)$ for the lateral tibiofemoral force integral, with this value being greater in male runners.

\section{Patellofemoral joint}

A main effect of ORTHOTIC $\left(P<0.05, p \eta^{2}=0.09\right)$ was found for peak patellofemoral force. Post-hoc

Table 3. Achilles tendon, loading rate and tibial acceleration parameters (Mean and SD) for each orthotic condition

\begin{tabular}{|c|c|c|c|c|c|c|c|c|c|c|c|}
\hline & \multirow{2}{*}{\multicolumn{10}{|c|}{ Female }} & \\
\hline & & & & & & & & & & & \\
\hline & \multicolumn{2}{|c|}{ Medial } & \multicolumn{2}{|c|}{ Lateral } & \multicolumn{2}{|c|}{ No-orthoses } & \multicolumn{2}{|c|}{ Semi-custom } & \multicolumn{2}{|c|}{ Off-the-shelf } & \\
\hline & Mean & SD & Mean & SD & Mean & SD & Mean & SD & Mean & SD & \\
\hline Comfort & 5.92 & 2.91 & 6.00 & 3.33 & & & 11.83 & 2.21 & 10.33 & 3.20 & $\mathrm{~A}$ \\
\hline \begin{tabular}{|l|} 
External instantaneous \\
load rate $[\mathrm{N} / \mathrm{kg} / \mathrm{s}]$
\end{tabular} & 1480.45 & 525.84 & 1383.08 & 356.07 & 1562.52 & 431.02 & 1552.99 & 419.77 & 1290.60 & 395.12 & A \\
\hline $\begin{array}{l}\text { Peak tibial } \\
\text { acceleration }[\mathrm{g}]\end{array}$ & 7.09 & 2.26 & 7.35 & 1.95 & 7.07 & 1.88 & 7.93 & 1.94 & 6.91 & 1.71 & A, B \\
\hline $\begin{array}{l}\text { Peak Achilles tendon } \\
\text { force }[\mathrm{N} / \mathrm{kg}]\end{array}$ & 75.54 & 10.23 & 75.77 & 6.75 & 76.19 & 14.36 & 77.77 & 13.95 & 78.64 & 11.56 & B \\
\hline \begin{tabular}{|l} 
Peak Achilles tendon \\
stress $[\mathrm{KPa} / \mathrm{kg}]$
\end{tabular} & 1569.68 & 212.50 & 1574.58 & 140.27 & 1583.26 & 298.50 & 1616.16 & 289.90 & 1634.15 & 240.26 & B \\
\hline \begin{tabular}{|l|} 
Achilles tendon \\
instantaneous load rate \\
{$[\mathrm{N} / \mathrm{kg} / \mathrm{s}]$}
\end{tabular} & 1650.18 & 445.92 & 1539.91 & 239.20 & 1703.98 & 550.80 & 1587.40 & 309.96 & 1632.10 & 415.57 & B \\
\hline \begin{tabular}{|l|} 
Achilles tendon stress \\
instantaneous load rate \\
{$[\mathrm{KPa} / \mathrm{kg} / \mathrm{s}]$}
\end{tabular} & 34290.99 & 9266.24 & 31999.52 & 4970.71 & 35408.90 & 11445.66 & 32986.31 & 6440.98 & 33915.23 & 8635.62 & B \\
\hline $\begin{array}{l}\text { Achilles tendon force } \\
\text { integral }[\mathrm{N} / \mathrm{kg} \cdot \mathrm{s}]\end{array}$ & 7.80 & 1.42 & 7.94 & 0.74 & 7.84 & 1.88 & 8.26 & 1.72 & 8.19 & 1.46 & B \\
\hline \multirow[t]{4}{*}{$\begin{array}{l}\text { Achilles tendon stress } \\
\text { integral }[\mathrm{KPa} / \mathrm{kg} \cdot \mathrm{s}]\end{array}$} & 162.13 & 29.53 & 164.96 & 15.45 & 162.93 & 39.17 & 171.60 & 35.68 & 170.27 & 30.30 & B \\
\hline & \multicolumn{10}{|c|}{ Female } & \\
\hline & \multicolumn{2}{|c|}{ Medial } & \multicolumn{2}{|c|}{ Lateral } & \multicolumn{2}{|c|}{ No-orthoses } & \multicolumn{2}{|c|}{ Semi-custom } & \multicolumn{2}{|c|}{ Off-the-shelf } & \\
\hline & Mean & SD & Mean & SD & Mean & SD & Mean & SD & Mean & SD & \\
\hline Comfort & 5.45 & 3.91 & 6.65 & 3.45 & & & 11.95 & 3.32 & 10.45 & 2.87 & A \\
\hline $\begin{array}{l}\text { External instantaneous } \\
\text { load rate }[\mathrm{N} / \mathrm{kg} / \mathrm{s}]\end{array}$ & 1767.05 & 950.24 & 1629.06 & 600.96 & 1669.17 & 648.25 & 1704.37 & 526.02 & 1567.10 & 712.42 & A \\
\hline \begin{tabular}{|l|} 
Peak tibial \\
acceleration $[\mathrm{g}]$
\end{tabular} & 8.72 & 2.15 & 8.90 & 2.21 & 8.70 & 2.42 & 9.01 & 2.12 & 8.55 & 2.09 & A, B \\
\hline $\begin{array}{l}\text { Peak Achilles tendon } \\
\text { force }[\mathrm{N} / \mathrm{kg}]\end{array}$ & 61.53 & 12.32 & 61.39 & 10.86 & 60.93 & 11.67 & 61.96 & 12.60 & 60.89 & 10.26 & B \\
\hline $\begin{array}{l}\text { Peak Achilles tendon } \\
\text { stress }[\mathrm{KPa} / \mathrm{kg}]\end{array}$ & 1278.52 & 255.94 & 1275.66 & 225.70 & 1266.16 & 242.42 & 1287.52 & 261.73 & 1265.29 & 213.26 & B \\
\hline \begin{tabular}{|l|} 
Achilles tendon \\
instantaneous load rate \\
{$[\mathrm{N} / \mathrm{kg} / \mathrm{s}]$}
\end{tabular} & 1285.07 & 327.89 & 1211.65 & 244.72 & 1136.86 & 270.52 & 1286.43 & 348.36 & 1244.78 & 322.38 & B \\
\hline \begin{tabular}{|l|} 
Achilles tendon stress \\
instantaneous load rate \\
{$[\mathrm{KPa} / \mathrm{kg} / \mathrm{s}]$}
\end{tabular} & 26703.86 & 6813.52 & 25178.27 & 5085.26 & 23624.08 & 5621.48 & 26732.19 & 7239.00 & 25866.78 & 6699.04 & B \\
\hline $\begin{array}{l}\text { Achilles tendon force } \\
\text { integral }[\mathrm{N} / \mathrm{kg} \cdot \mathrm{s}]\end{array}$ & 6.81 & 1.61 & 6.84 & 1.40 & 6.66 & 1.66 & 6.82 & 1.66 & 6.70 & 1.34 & B \\
\hline $\begin{array}{l}\text { Achilles tendon stress } \\
\text { integral }[\mathrm{KPa} / \mathrm{kg} \cdot \mathrm{s}]\end{array}$ & 141.50 & 33.37 & 142.06 & 29.11 & 138.40 & 34.40 & 141.64 & 34.43 & 139.33 & 27.75 & B \\
\hline
\end{tabular}

Key: A = main effect of ORTHOSES, B = main effect of GENDER. 
pairwise comparisons showed that peak patellofemoral force was significantly larger in the lateral condition $(P=0.039)$, compared to the off-the-shelf orthoses. For peak patellofemoral stress there was a main effect of ORTHOTIC $\left(P<0.05, p \eta^{2}=0.09\right)$. Post-hoc pairwise comparisons showed that peak patellofemoral stress was significantly larger in the lateral condition $(P=0.04)$ compared to the off the shelf orthoses. In addition, there was also a main effect of GENDER $\left(P<0.05, p \eta^{2}=0.35\right)$, with peak stress being greater in females. For the patellofemoral stress instantaneous loading rate, a main effect of GENDER $(P<0.05$, $p \eta^{2}=0.25$ ) was found, with this parameter being greater in females. For the patellofemoral force integral a main effect of ORTHOTIC $\left(P<0.05, p \eta^{2}=0.10\right)$ was found. Post-hoc pairwise comparisons showed that patellofemoral force integral was significantly larger in the lateral condition, compared to no orthotic $(P=0.04)$ off the shelf orthoses $(P=0.018)$. There was also a main effect of ORTHOTIC $\left(P<0.05, p \eta^{2}\right.$ $=0.09$ ) for the patellofemoral stress integral. Post-hoc pairwise comparisons showed that the patellofemoral stress integral was significantly larger in the lateral condition $(P=0.015)$, compared to the off the shelf orthoses. In addition, there was also a main effect of GENDER $\left(P<0.05, p \eta^{2}=0.37\right)$, the patellofemoral stress integral being greater in females.

\section{Ankle joint}

At the ankle, there was a main effect of GENDER $\left(P<0.05, p \eta^{2}=0.36\right)$ for the peak ankle force, with this measurement being larger in males. For the integral of the ankle force $\left(P<0.05, p \eta^{2}=0.24\right)$, a main effect of GENDER was found, with the ankle force integral being larger in males.

\section{Achilles tendon kinetics}

There was a main effect of GENDER for both the peak Achilles tendon force $\left(P<0.05, p \eta^{2}=0.41\right)$ and stress $\left(P<0.05, p \eta^{2}=0.40\right)$, with both parameters being greater in male runners. In addition, there was a main effect of GENDER for both the Achilles tendon force $\left(P<0.05, p \eta^{2}=0.36\right)$ and stress $(P<0.05$, $\left.p \eta^{2}=0.35\right)$ instantaneous loading rates, with both parameters being greater in male runners. Finally, for the integral of the Achilles tendon force $(P<0.05$, $\left.p \eta^{2}=0.18\right)$ and stress $\left(P<0.05, p \eta^{2}=0.19\right)$, a main effect of GENDER was found, with both measures being larger in males.

\section{External instantaneous loading rate and tibial accelerations}

For the external instantaneous loading rate, there was a main effect for ORTHOTIC $(P<0.05$, $\left.p \eta^{2}=0.10\right)$. Post-hoc pairwise comparisons showed that the instantaneous loading rate was significantly greater in the medial $(P=0.028)$ and semi-custom $(P=0.03)$ conditions compared to the off-the-shelf orthoses. For peak tibial acceleration, there was a main effect for ORTHOTIC $\left(P<0.05, p \eta^{2}=0.11\right)$. Post-hoc pairwise comparisons showed that the peak tibial accelerations were significantly greater in the semi-custom $(P<0.001)$ conditions compared to the off-the-shelf orthoses. In addition, there was also a main effect of GENDER $\left(P<0.05, p \eta^{2}=0.13\right)$, with tibial accelerations being greater in females.

\section{Subjective ratings}

There was a main effect of ORTHOTIC $(P<0.05$, $\left.p \eta^{2}=0.51\right)$ for participants ratings of comfort. Post-hoc pairwise comparisons showed that the semi-custom $(P<0.001$ and $P<0.001)$ and off-the-shelf $(P<0.001$ and $P<0.001)$ orthoses were rated as being significantly more comfortable than the medial and lateral conditions. Finally, the semi-custom orthoses were rated as being significantly $(P=0.029)$ more comfortable than the off-the-shelf condition. In addition, the Chi-squared analysis of orthotic preferences was significant $\left(\chi_{(3)}^{2}=22.00, P<0.05\right)$ with 19 participants selecting the semi-custom orthoses, 12 off-the-shelf, 4 medial and 1 the lateral conditions.

\section{Joint kinematics}

\section{Hip}

For the peak hip adduction angle there was a main effect of ORTHOTIC $\left(P<0.05, p \eta^{2}=0.20\right)$. Post-hoc pairwise comparisons showed that peak adduction was significantly greater in the lateral and semi-custom orthoses compared to the medial $(P<0.001$ and $P=0.002)$, no orthotic $(P=0.002$ and $P=0.036)$ and off-the-shelf orthoses $(P<0.001$ and $P<0.001)$. There was also a main effect of GENDER $(P<0.05$, $\left.p \eta^{2}=0.14\right)$, with peak adduction being larger in females.

\section{Knee}

For the sagittal knee angle at footstrike there was a main effect of GENDER $\left(P<0.05, p \eta^{2}=0.18\right)$, with knee flexion being larger in females. There was also a main effect of GENDER $\left(P<0.05, p \eta^{2}=0.20\right)$ for the peak knee flexion angle, which was shown to be greater in females. There was also a main effect of ORTHOTIC $\left(P<0.05, p \eta^{2}=0.11\right)$ for the peak knee abduction angle. Post-hoc pairwise comparisons showed that peak abduction was significantly larger in the lateral $(P=0.032)$ and semi-custom orthoses $(P=0.01)$ compared to the no orthotic condition. 


\section{Ankle}

For the sagittal ankle angle at footstrike there was a main effect of GENDER $\left(P<0.05, p \eta^{2}=0.25\right)$, with dorsiflexion being larger in females. In addition, there was also a main effect of ORTHOTIC $(P<0.05$, $\left.p \eta^{2}=0.13\right)$ for the peak dorsiflexion angle. Post-hoc pairwise comparisons showed that peak dorsiflexion was significantly greater in the medial orthoses compared to the lateral $(P=0.04)$, no orthotic $(P=0.028)$, off-the-shelf $(P=0.012)$ and semi-custom $(P=0.01)$ conditions. There was also a main effect of GENDER $\left(P<0.05, p \eta^{2}=0.22\right)$ for dorsiflexion ROM, with this measurement being larger in males.

For the peak eversion angle there was a main effect of ORTHOTIC $\left(P<0.05, p \eta^{2}=0.26\right)$. Post-hoc pairwise comparisons showed that peak eversion was significantly greater in the lateral $(P<0.001)$, no orthotic $(P<0.001)$, off-the-shelf $(P<0.032)$ and semi-custom $(P<0.001)$ conditions compared to medial orthoses. In addition, for the eversion ROM there was a main effect of ORTHOTIC $\left(P<0.05, p \eta^{2}=0.61\right)$. Post-hoc pairwise comparisons showed that eversion
ROM was significantly greater in the lateral $(P<0.001)$, no orthotic $(P<0.001)$, off-the-shelf $(P<0.001)$ and semi-custom $(P<0.001)$ conditions compared to the medial orthoses. In addition, peak eversion was significantly larger in the lateral orthoses compared to the off-the-shelf $(P<0.001)$, semi-custom $(P<0.001)$ and no orthotic $(P=0.005)$ conditions.

\section{Tibial internal rotation}

For the peak tibial internal rotation angle there was a main effect of ORTHOTIC $\left(P<0.05, p \eta^{2}=0.28\right)$. Post-hoc pairwise comparisons showed that peak tibial internal rotation was significantly greater in the lateral orthoses compared to the medial $(P<0.001)$ no orthotic $(P<0.001)$, off-the-shelf $(P<0.001)$ and semicustom $(P<0.017)$ conditions. In addition, peak tibial internal rotation was significantly greater in the semi-custom orthoses compared to the medial $(P<0.001)$ and off-the-shelf $(P=0.001)$ conditions. In addition, for the tibial internal rotation ROM there was a main effect of ORTHOTIC $\left(P<0.05, p \eta^{2}=0.30\right)$. Post-hoc pairwise comparisons showed that tibial internal

Table 4. Three-dimensional hip joint kinematics (Mean and SD) for each orthotic condition

\begin{tabular}{|c|c|c|c|c|c|c|c|c|c|c|c|}
\hline & \multicolumn{10}{|c|}{ Male } & \\
\hline & \multicolumn{2}{|c|}{ Medial } & \multicolumn{2}{|c|}{ Lateral } & \multicolumn{2}{|c|}{ No-orthoses } & \multicolumn{2}{|c|}{ Semi-custom } & \multicolumn{2}{|c|}{ Off-the-shelf } & \\
\hline & Mean & SD & Mean & SD & Mean & SD & Mean & SD & Mean & SD & \\
\hline \multicolumn{12}{|l|}{\begin{tabular}{|l} 
Sagittal plane \\
\end{tabular}} \\
\hline Angle at footstrike $\left[{ }^{\circ}\right]$ & 38.15 & 14.28 & 39.36 & 13.40 & 38.07 & 14.42 & 40.77 & 8.41 & 37.69 & 12.84 & \\
\hline Peak flexion $\left[{ }^{\circ}\right]$ & 38.77 & 14.08 & 39.90 & 13.32 & 38.34 & 14.04 & 41.20 & 8.26 & 38.33 & 12.33 & \\
\hline $\operatorname{ROM}\left[^{\circ}\right]$ & 0.62 & 1.26 & 0.54 & 1.04 & 0.28 & 0.60 & 0.43 & 0.67 & 0.63 & 1.06 & \\
\hline \multicolumn{12}{|l|}{ Coronal plane } \\
\hline Angle at footstrike $\left[^{\circ}\right]$ & -0.04 & 8.99 & 1.02 & 8.93 & 0.07 & 9.69 & 1.64 & 6.75 & -0.21 & 9.05 & \\
\hline Peak adduction $\left[{ }^{\circ}\right]$ & 7.77 & 8.57 & 9.18 & 7.79 & 7.70 & 8.68 & 9.75 & 5.98 & 7.41 & 7.65 & A, B \\
\hline ROM [ [ $]$ & 7.81 & 5.40 & 8.16 & 4.59 & 7.63 & 4.02 & 8.11 & 4.21 & 7.62 & 3.89 & \\
\hline \multicolumn{12}{|l|}{ Transverse plane } \\
\hline Angle at footstrike $\left[{ }^{\circ}\right]$ & 4.54 & 11.41 & 3.33 & 11.42 & 6.03 & 10.87 & 3.19 & 12.37 & 3.97 & 11.71 & \\
\hline Peak external rotation $\left[^{\circ}\right]$ & -7.67 & 12.12 & -7.43 & 12.63 & -5.91 & 11.27 & -9.01 & 12.78 & -7.57 & 12.76 & \\
\hline \multirow[t]{4}{*}{$\operatorname{ROM}\left[{ }^{\circ}\right]$} & 12.22 & 6.11 & 10.76 & 6.29 & 11.95 & 6.70 & 12.20 & 6.55 & 11.54 & 5.06 & \\
\hline & \multicolumn{10}{|c|}{ Female } & \\
\hline & \multicolumn{2}{|c|}{ Medial } & \multicolumn{2}{|c|}{ Lateral } & \multicolumn{2}{|c|}{ No-orthoses } & \multicolumn{2}{|c|}{ Semi-custom } & \multicolumn{2}{|c|}{ Off-the-shelf } & \\
\hline & Mean & SD & Mean & $\mathrm{SD}$ & Mean & $\mathrm{SD}$ & Mean & $\mathrm{SD}$ & Mean & SD & \\
\hline \multicolumn{12}{|l|}{ Sagittal plane } \\
\hline Angle at footstrike $\left[{ }^{\circ}\right]$ & 46.66 & 9.69 & 47.82 & 11.08 & 46.53 & 10.75 & 46.03 & 12.02 & 46.24 & 11.90 & \\
\hline Peak flexion $\left[{ }^{\circ}\right]$ & 47.15 & 9.52 & 48.41 & 10.56 & 47.05 & 10.00 & 47.00 & 11.04 & 47.07 & 10.84 & \\
\hline $\operatorname{ROM}\left[{ }^{\circ}\right]$ & 0.49 & 0.86 & 0.59 & 1.20 & 0.52 & 1.35 & 0.97 & 1.92 & 0.83 & 2.19 & \\
\hline \multicolumn{12}{|l|}{ Coronal plane } \\
\hline Angle at footstrike $\left[{ }^{\circ}\right]$ & 4.75 & 5.87 & 4.40 & 5.76 & 3.56 & 6.23 & 3.70 & 5.99 & 3.78 & 5.62 & \\
\hline Peak adduction $\left[^{\circ}\right]$ & 12.42 & 4.93 & 14.18 & 4.39 & 12.73 & 4.65 & 13.31 & 4.35 & 12.25 & 4.24 & A, B \\
\hline $\mathrm{ROM}\left[{ }^{\circ}\right]$ & 7.67 & 3.05 & 9.78 & 4.00 & 9.17 & 3.53 & 9.61 & 3.74 & 8.47 & 4.01 & \\
\hline \multicolumn{12}{|l|}{ Transverse plane } \\
\hline Angle at footstrike $\left[{ }^{\circ}\right]$ & 10.86 & 8.21 & 10.52 & 8.32 & 10.01 & 7.35 & 10.06 & 8.92 & 11.23 & 8.97 & \\
\hline Peak external rotation $\left[{ }^{\circ}\right]$ & -2.66 & 7.98 & -3.12 & 7.96 & -1.68 & 7.72 & -3.33 & 7.73 & -2.80 & 8.11 & \\
\hline $\operatorname{ROM}\left[{ }^{\circ}\right]$ & 13.52 & 6.42 & 13.63 & 6.67 & 11.69 & 6.30 & 13.39 & 6.54 & 14.04 & 7.54 & \\
\hline
\end{tabular}

Key: A = main effect of ORTHOSES, $\mathrm{B}=$ main effect of GENDER 
Table 5. Three-dimensional knee joint kinematics (Mean and SD) for each orthotic condition

\begin{tabular}{|c|c|c|c|c|c|c|c|c|c|c|c|}
\hline & \multicolumn{10}{|c|}{ Male } & \\
\hline & \multicolumn{2}{|c|}{ Medial } & \multicolumn{2}{|c|}{ Lateral } & \multicolumn{2}{|c|}{ No-orthoses } & \multicolumn{2}{|c|}{ Semi-custom } & \multicolumn{2}{|c|}{ Off-the-shelf } & \\
\hline & Mean & SD & Mean & SD & Mean & $\mathrm{SD}$ & Mean & SD & Mean & $\mathrm{SD}$ & \\
\hline \multicolumn{12}{|l|}{ Sagittal plane } \\
\hline Angle at footstrike $\left[{ }^{\circ}\right]$ & 14.66 & 5.66 & 16.21 & 6.05 & 13.92 & 6.54 & 15.27 & 6.29 & 14.34 & 6.64 & $\mathrm{~B}$ \\
\hline Peak flexion $\left[{ }^{\circ}\right]$ & 43.35 & 6.04 & 44.28 & 6.05 & 42.71 & 5.89 & 43.79 & 5.13 & 43.48 & 5.76 & B \\
\hline $\mathrm{ROM}\left[^{\circ}\right]$ & 28.69 & 4.70 & 28.07 & 4.33 & 28.79 & 4.94 & 28.52 & 6.05 & 29.14 & 4.83 & \\
\hline \multicolumn{12}{|l|}{ Coronal plane } \\
\hline Angle at footstrike $\left[{ }^{\circ}\right]$ & 1.22 & 4.96 & 1.06 & 4.15 & 1.58 & 4.96 & 0.44 & 4.55 & 1.60 & 4.82 & \\
\hline Peak adduction $\left[{ }^{\circ}\right]$ & -5.96 & 5.37 & -6.24 & 5.67 & -5.27 & 4.85 & -6.64 & 5.48 & -5.49 & 5.33 & A \\
\hline $\mathrm{ROM}\left[{ }^{\circ}\right]$ & 7.18 & 3.06 & 7.29 & 3.69 & 6.85 & 4.05 & 7.07 & 3.02 & 7.09 & 2.60 & \\
\hline \multicolumn{12}{|l|}{ Transverse plane } \\
\hline Angle at footstrike $\left[{ }^{\circ}\right]$ & -12.87 & 8.16 & -11.55 & 6.23 & -15.75 & 7.95 & -11.96 & 8.11 & -13.42 & 8.55 & \\
\hline Peak external rotation $\left[{ }^{\circ}\right]$ & 7.50 & 9.35 & 8.24 & 9.18 & 8.01 & 8.54 & 8.36 & 9.80 & 7.96 & 8.78 & \\
\hline \multirow[t]{4}{*}{$\mathrm{ROM}\left[{ }^{\circ}\right]$} & 20.38 & 5.41 & 19.80 & 6.16 & 23.76 & 5.73 & 20.32 & 6.95 & 21.38 & 5.75 & \\
\hline & \multicolumn{10}{|c|}{ Female } & \\
\hline & \multicolumn{2}{|c|}{ Medial } & \multicolumn{2}{|c|}{ Lateral } & \multicolumn{2}{|c|}{ No-orthoses } & \multicolumn{2}{|c|}{ Semi-custom } & \multicolumn{2}{|c|}{ Off-the-shelf } & \\
\hline & Mean & SD & Mean & SD & Mean & $\mathrm{SD}$ & Mean & SD & Mean & $\mathrm{SD}$ & \\
\hline \multicolumn{12}{|l|}{ Sagittal plane } \\
\hline Angle at footstrike $\left[{ }^{\circ}\right]$ & 22.57 & 7.86 & 22.47 & 8.14 & 22.85 & 9.89 & 20.63 & 9.46 & 21.37 & 9.58 & $\mathrm{~B}$ \\
\hline Peak flexion $\left[^{\circ}\right]$ & 49.92 & 7.93 & 50.79 & 6.93 & 49.19 & 7.06 & 50.26 & 7.66 & 49.75 & 7.52 & $\mathrm{~B}$ \\
\hline $\mathrm{ROM}\left[^{\circ}\right]$ & 27.35 & 6.68 & 28.32 & 6.90 & 26.34 & 7.86 & 29.62 & 7.77 & 28.38 & 8.40 & \\
\hline \multicolumn{12}{|l|}{ Coronal plane } \\
\hline Angle at footstrike $\left[{ }^{\circ}\right]$ & 0.86 & 5.54 & 1.03 & 6.04 & 1.57 & 5.87 & 0.63 & 5.61 & 1.07 & 5.78 & \\
\hline Peak adduction $\left[{ }^{\circ}\right]$ & -6.89 & 4.76 & -7.31 & 5.18 & -6.19 & 3.65 & -7.14 & 4.78 & -6.86 & 4.49 & $\mathrm{~A}$ \\
\hline $\mathrm{ROM}\left[{ }^{\circ}\right]$ & 7.75 & 4.37 & 8.34 & 4.79 & 7.76 & 4.75 & 7.76 & 4.45 & 7.93 & 4.85 & \\
\hline \multicolumn{12}{|l|}{ Transverse plane } \\
\hline Angle at footstrike $\left[{ }^{\circ}\right]$ & -11.93 & 4.86 & -12.41 & 7.30 & -10.95 & 5.51 & -11.46 & 6.97 & -11.84 & 6.57 & \\
\hline Peak external rotation $\left[{ }^{\circ}\right]$ & 3.63 & 5.74 & 4.13 & 6.01 & 3.79 & 5.94 & 4.30 & 6.06 & 4.28 & 5.59 & \\
\hline $\mathrm{ROM}\left[^{\circ}\right]$ & 15.57 & 5.78 & 16.54 & 6.12 & 14.73 & 6.11 & 15.76 & 6.36 & 16.12 & 6.94 & \\
\hline
\end{tabular}

Key: A = main effect of ORTHOSES, B = main effect of GENDER.

Table 6. Three-dimensional ankle joint kinematics (Mean and SD) for each orthotic condition

\begin{tabular}{|c|c|c|c|c|c|c|c|c|c|c|c|}
\hline & \multicolumn{10}{|c|}{ Male } & \\
\hline & \multicolumn{2}{|c|}{ Medial } & \multicolumn{2}{|c|}{ Lateral } & \multicolumn{2}{|c|}{ No-orthoses } & \multicolumn{2}{|c|}{ Semi-custom } & \multicolumn{2}{|c|}{ Off-the-shelf } & \\
\hline & Mean & SD & Mean & SD & Mean & SD & Mean & SD & Mean & SD & \\
\hline \multicolumn{12}{|l|}{ Sagittal plane } \\
\hline Angle at footstrike $\left[{ }^{\circ}\right]$ & 2.27 & 15.37 & 2.28 & 16.05 & -1.87 & 15.77 & -2.21 & 16.39 & -0.51 & 16.40 & $\mathrm{~B}$ \\
\hline Peak dorsiflexion $\left[{ }^{\circ}\right]$ & 17.68 & 6.95 & 16.91 & 5.58 & 15.48 & 4.49 & 15.86 & 4.82 & 15.60 & 4.36 & A \\
\hline ROM [ $\left.{ }^{\circ}\right]$ & 15.41 & 11.26 & 14.64 & 12.56 & 17.36 & 14.02 & 18.06 & 15.52 & 16.11 & 13.77 & $\mathrm{~B}$ \\
\hline \multicolumn{12}{|l|}{\begin{tabular}{|l|} 
Coronal plane \\
\end{tabular}} \\
\hline Angle at footstrike $\left[{ }^{\circ}\right]$ & 1.93 & 5.00 & 4.40 & 3.98 & 4.68 & 3.91 & 3.64 & 4.04 & 3.75 & 3.91 & \\
\hline Peak eversion $\left[{ }^{\circ}\right]$ & -6.61 & 3.69 & -9.61 & 4.29 & -8.22 & 3.74 & -8.25 & 3.71 & -7.54 & 3.74 & $\mathrm{~A}$ \\
\hline $\operatorname{ROM}\left[^{\circ}\right]$ & 8.53 & 7.08 & 14.01 & 5.55 & 12.89 & 4.95 & 11.89 & 4.53 & 11.30 & 4.93 & $\mathrm{~A}$ \\
\hline \multicolumn{12}{|l|}{ Transverse plane } \\
\hline Angle at footstrike $\left[{ }^{\circ}\right]$ & -1.78 & 3.12 & -2.01 & 3.56 & 0.62 & 4.59 & -0.59 & 3.54 & 0.03 & 3.59 & \\
\hline Peak external rotation $\left[{ }^{\circ}\right]$ & -9.53 & 4.90 & -11.04 & 5.05 & -9.48 & 5.53 & -10.07 & 5.04 & -8.99 & 5.31 & \\
\hline $\mathrm{ROM}\left[^{\circ}\right]$ & 7.76 & 4.55 & 9.03 & 5.29 & 10.10 & 4.78 & 9.47 & 4.48 & 9.02 & 4.98 & \\
\hline Tibial internal rotation at footstrike $\left[{ }^{\circ}\right]$ & 8.47 & 5.58 & 8.16 & 5.51 & 7.11 & 5.52 & 8.00 & 5.48 & 7.28 & 5.54 & \\
\hline Peak tibial internal rotation $\left[{ }^{\circ}\right]$ & 15.73 & 5.10 & 17.40 & 5.54 & 15.85 & 5.54 & 16.43 & 5.66 & 15.40 & 5.34 & $\mathrm{~A}$ \\
\hline Peak tibial internal rotation $\mathrm{ROM}\left[{ }^{\circ}\right]$ & 7.27 & 3.46 & 9.24 & 4.79 & 8.74 & 3.61 & 8.42 & 3.86 & 8.12 & 4.13 & A \\
\hline
\end{tabular}


Table 6 continued

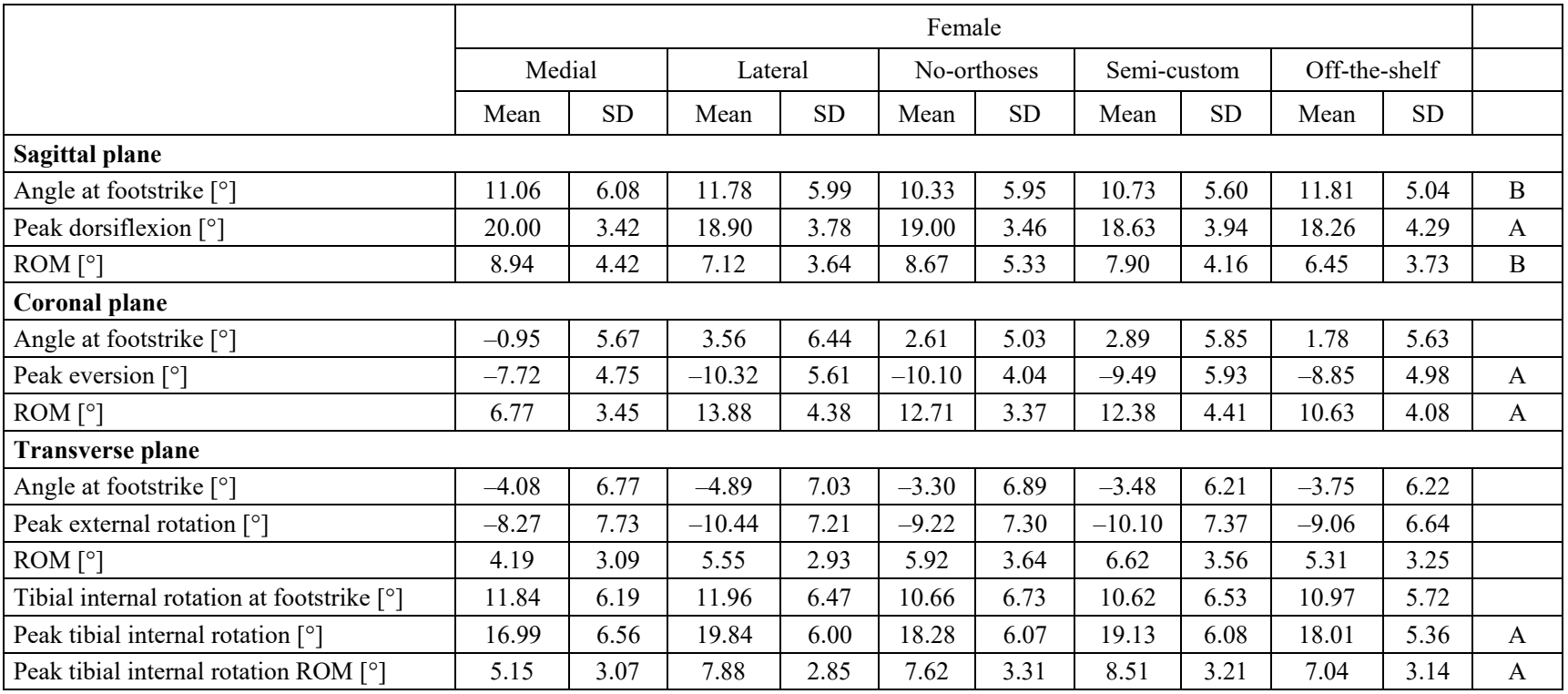

Key: A = main effect of ORTHOSES, B = main effect of GENDER.

rotation ROM was significantly greater in the lateral $(P<0.001)$, no orthotic $(P<0.001)$, off-the-shelf $(P=0.001)$ and semi-custom $(P<0.001)$ conditions compared to the medial orthoses. In addition, tibial internal rotation ROM was also significantly greater in the lateral $(P=0.04)$, no orthotic $(P=0.027)$ and semi-custom orthoses $(P=0.001)$ compared to the off-the-shelf condition.

\section{Discussion}

This study aimed to examine the effects of different orthotic conditions on the biomechanical mechanisms linked to the aetiology of chronic pathologies. To the authors' knowledge, this is the first investigation to collectively explore the effects of different orthoses on lower extremity kinetics and kinematics during running, and may provide insight into the potential efficacy of different foot orthoses for the prevention chronic running pathologies.

Patellofemoral pain is regarded as the most common chronic running injury [32]. Females are renowned for being at increased risk from patellofemoral disorders, therefore, it is important that the current investigation showed female runners to be associated with increased patellofemoral loading. This observation concurs with those of Sinclair and Selfe, [26] and, given the proposed relationship between joint stress and patellofemoral pathology [9], appears to provide insight into the responsible factors for the increased incidence of patellofemoral pain in females. In support of the findings of Sinclair, [29], the current investigation also showed that patellofemoral joint stress parameters were significantly greater when running in the lateral orthoses in relation to running in off the shelf devices. Although the mean difference between these orthotic conditions was relatively small, this observation may nonetheless be clinically important, as patellofemoral pain symptoms are believed to be initiated via excessive/repeated patellofemoral joint stress [9]. The current study indicates that running with off-the-shelf orthoses may be preferable over lateral wedged devices, as a mechanism to reduce the risk from the biomechanical parameters linked to the aetiology of patellofemoral pain in runners.

At the tibiofemoral joint, there was no effect of orthoses at the medial aspect. This opposes previous walking analyses, which have consistently shown that lateral orthoses reduce the magnitude of the external knee adduction moment [16]. It is proposed that the difference between analyses relates to the manner in which tibiofemoral loading was calculated in the current study, as previous analyses have used coronal plane joint torques as a pseudo measure of medial compartment loading, which do not account for muscular co-contraction about the knee joint [14]. However, at the lateral aspect of the tibiofemoral joint compressive loading was significantly greater in the lateral orthoses in relation to the medial devices. This indicates that although lateral orthoses were not able to attenuate compressive loading at the medial aspect of the joint, they were able to transfer load to the lat- 
eral tibiofemoral compartment. Therefore, although the increases in compressive load were small, lateral wedged devices may place runners at greater risk from the mechanisms associated with tibiofemoral pathologies. Furthermore, in contrast to the findings at the patellofemoral joint, this investigation showed that at both the medial and lateral aspects of the tibiofemoral joint males were associated with statistically greater joint loading parameters in relation to females, leading to the conclusion that males are at greater risk from the biomechanical parameters linked to the aetiology of tibiofemoral pathologies.

In agreement with the findings of Greenhalgh and Sinclair [11], the current study also showed that males were associated with increased Achilles tendon stress and ankle joint force parameters. In contrast to patellofemoral pathologies, males are at increased risk from Achilles tendinopathies in relation to age-matched females [13]. Given the proposed association between tendon stress and the physiological initiation of tendinous collagen degradation [1], this observation appears to provide further insight into the biomechanical mechanisms behind the increased incidence Achilles tendinopathy in males. However, as there were no significant differences between orthoses in ankle or Achilles tendon load parameters, the observations from this investigation are in contrast to those of Sinclair et al. [25], who showed that off-the-shelf orthoses significantly reduced peak Achilles tendon force, but agree with those of Sinclair et al. [26] with regards to semi-custom devices. As such, the findings from this study using musculoskeletal simulation indicate that foot orthoses do not influence the biomechanical parameters linked to the aetiology of ankle/Achilles tendon pathologies during running.

Importantly, in agreement with the findings of Mündermann et al. [23] and Sinclair et al. [25], this study also showed that instantaneous loading rates and peak tibial accelerations were significantly larger in the medial and semi-custom conditions compared to off-theshelf orthoses. Excessive tibial accelerations/vertical rates of loading are the biomechanical mechanisms responsible for the development of stress fractures [35].

Therefore, this study indicates that off-the-shelf orthoses may be effective in attenuating the mechanisms linked to the aetiology of tibial stress fractures in runners. In addition, that females were associated with increased tibial accelerations may also be clinically important taking into account their proposed link to the aetiology of stress fractures, and may provide further insight into the biomechanical mechanisms responsible for the increased incidence of stress fractures in female runners [17].

\section{Conclusions}

In conclusion, although the biomechanical effects of foot orthoses have been previously examined, current knowledge with regards to the effects of different orthoses is limited. This study therefore adds to the current literature by examining the influence of different orthoses on the biomechanical mechanisms linked to the aetiology of chronic pathologies, using musculoskeletal simulation. The current investigation importantly showed that patellofemoral stress parameters and loading rates/peak tibial accelerations were significantly reduced in the off the shelf orthoses and lateral tibiofemoral loading parameters were significantly attenuated in the medial orthotic condition. Therefore, the current investigation indicates that different orthotic devices/configurations may provide distinct benefits in terms of their effectiveness in attenuating the biomechanical parameters linked to the aetiology of chronic running injuries.

\section{References}

[1] Abate M., Silbernagel K.G., Siljeholm C., Di Iorio A., De Amicis D., Salini V., Paganelli R., Pathogenesis of tendinopathies: inflammation or degeneration?, Arthritis Res. Ther., 2009, 11, 235-240.

[2] Almonroeder T., Willson J.D., KernozeK T.W., The effect of foot strike pattern on Achilles tendon load during running, Ann. Biomed. Eng., 2013, 41, 1758-1766.

[3] Almonroeder T.G., Benson L.C., O'Connor K.M., The influence of a prefabricated foot orthosis on lower extremity mechanics during running in individuals with varying dynamic foot motion, J. Orthop. Sports Phys. Ther., 2016, 46, 749-755.

[4] Besier T.F., DraPer C.E., Gold G.E., Beaupre G.S., Delp S.L., Patellofemoral joint contact area increases with knee flexion and weight-bearing, J. Orthop. Res., 2005, 23, 345-350.

[5] Bonanno D.R., Murley G.S., Munteanu S.E., Landorf K.B., MENZ H.B., Effectiveness of foot orthoses for the prevention of lower limb overuse injuries in naval recruits: a randomised controlled trial, Br. J. Sports Med., 2018, 52, 298-302.

[6] Butler R.J., Davis I., Laughton C.M., Hughes M., Dualfunction foot orthosis: effect on shock and control of rearfoot motion, Foot Ankle Int., 2003, 24, 410-414.

[7] Delp S.L., Anderson F.C., ARnold A.S., LoAn P., Habib A., JoHN C.T., THELEN D.G., OpenSim: open-source software to create and analyze dynamic simulations of movement, IEEE Trans. Biomed. Eng., 2007, 54, 1940-1950.

[8] Eslami M., Begon M., Farahpour N., Allard P., Forefootrearfoot coupling patterns and tibial internal rotation during stance phase of barefoot versus shod running, Clin. Biomech., 2007, 22, 74-80.

[9] Farrokhi S., KeyaK J.H., Powers C.M., Individuals with patellofemoral pain exhibit greater patellofemoral joint stress: a finite element analysis study, Osteoarthritis Cartilage, 2011, 19, 287-294. 
[10] Franklyn-Miller A., Wilson C., Bilzon J., McCrory P. Foot orthoses in the prevention of injury in initial military training: a randomized controlled trial, Am. J. Sport Med., 2011, 39, 30-37.

[11] Greenhalgh A., Sinclair J., Comparison of Achilles tendon loading between male and female recreational runners, J. Human Kin., 2014, 44, 155-159.

[12] Hamstra-Wright K.L., Bliven K.C.H., BAY C., Risk factors for medial tibial stress syndrome in physically active individuals such as runners and military personnel: a systematic review and meta-analysis, Br. J. Sports Med., 2015, 49, 362-369.

[13] Hess G.W., Achilles tendon rupture: a review of etiology, population, anatomy, risk factors, and injury prevention, Foot Ankle Spec., 2010, 3, 29-32.

[14] Herzog W., LOngino D., Clark A., The role of muscles in joint adaptation and degeneration, Langenbecks Arch. Surg., 2003, 388, 305-315.

[15] Hinman R.S., Lentzos J., Vicenzino B., Crossley K.M., Is patellofemoral osteoarthritis common in middle-aged people with chronic patellofemoral pain?. Arthritis Care Res., 2014, $66,1252-1257$.

[16] Jones R.K., Nester C.J., Richards J.D., Kim W.Y., JOHNSON D.S., JARI S., TYSON S.F., A comparison of the biomechanical effects of valgus knee braces and lateral wedged insoles in patients with knee osteoarthritis, Gait Posture, 2013, 37, 368-372.

[17] Jones B.H., BoveE M.W., Harris J.M., COWAN D.N., Intrinsic risk factors for exercise-related injuries among male and female army trainees, Am. J. Sports Med., 1993, 21, 705-710.

[18] Laughton C.A., Davis I.M., Hamill J., Effect of strike pattern and orthotic intervention on tibial shock during running, J. Appl. Biomech., 2003, 19, 153-168.

[19] Lerner Z.F., DeMers M.S., Delp S.L., Browning R.C., How tibiofemoral alignment and contact locations affect predictions of medial and lateral tibiofemoral contact forces, J. Biomech., 2015, 48, 644-650.

[20] Lopes A.D., Hespanhol L.C. Junior, Yeung S.S., Costa L.O., What are the main running-related musculoskeletal injuries? A systematic review, Sports Med., 2012, 42, 891-905.

[21] Milgrom Y., Milgrom C., Altaras T., Globus O., ZeltZer E., Finestone A.S., Achilles tendons hypertrophy in response to high loading training, Foot Ankle Int., 2014, 35, 1303-1308.

[22] Morgenroth D.C., Medverd J.R., Seyedali M., CZERNIECKI J.M., The relationship between knee joint loading rate during walking and degenerative changes on magnetic resonance imaging, Clin. Biomech., 2014, 29, 664-670.
[23] Mündermann A., Nigg B.M., Humble R.N., Stefanyshyn D.J., Foot orthotics affect lower extremity kinematics and kinetics during running, Clin. Biomech., 2003, 18, 254-262.

[24] Sinclair J., Greenhalgh A., Brooks D., Edmundson C.J., HoBBS S.J., The influence of barefoot and barefoot-inspired footwear on the kinetics and kinematics of running in comparison to conventional running shoes, Footwear Sci., 2013, $5,45-53$.

[25] Sinclair J., ISHERWOOD J., TAYLOR P.J., Effects of foot orthoses on Achilles tendon load in recreational runners, Clin. Biomech., 2014, 29, 956-958.

[26] Sinclair J., Selfe J., Sex differences in knee loading in recreational runners, J. Biomech., 2015, 48, 2171-2175.

[27] Sinclair J., SHORE H., Richards J., Effects of semi-custom and off-the-shelf orthoses on Achilles tendon and patellofemoral kinetics in female runners, Balt. J. Health Phys. Act., 2016, 8, 7-15.

[28] SinclaIR J., Effects of medial and lateral orthoses on kinetics and tibiocalcaneal kinematics in male runners, FAOJ, 2017, $10,1-19$.

[29] SinCLAIR J., Mechanical effects of medial and lateral wedged orthoses during running, Phys. Ther. Sport., 2018, 32, 48-53.

[30] Sinclair J., Stainton P., Effects of medial and lateral wedged orthoses on knee and ankle joint loading in female runners, Kinesiology, 2019 (in Press).

[31] Sinclair J., JansSen J., Richards J.D., Butters B., TAYLOR P.J., HoBBS S.J., Effects of a 4-week intervention using semicustom insoles on perceived pain and patellofemoral loading in targeted subgroups of recreational runners with patellofemoral pain, Phys. Ther. Sport, 2018, 34, 21-27.

[32] Snyder R.A., Koester M.C., Dunn W.R., Epidemiology of stress fractures, Clin. Sports Med., 2006, 25, 37-52.

[33] Taunton J.E., Ryan M.B., Clement D.B., McKenzie D.C., Lloyd-SMith D.R., ZuMBo B.D., A retrospective casecontrol analysis of 2002 running injuries, Br. J. Sports Med., 2002, 36, 95-101.

[34] Van Ginckel A., Thiss Y., Hesar N.G.Z., Mahieu N., De Clerce D., Roosen P., Witvrouw E., Intrinsic gaitrelated risk factors for Achilles tendinopathy in novice runners: a prospective study, Gait Posture, 2008, 29, 387-391.

[35] Warden S.J., BurR D.B., BruKner P.D., Stress fractures: pathophysiology, epidemiology, and risk factors, Curr. Osteoporos. Rep., 2006, 4, 103-109.

[36] Wise B.L., Niu J., Yang M., Lane N.E., Harvey W., FELSON D.T., LEWIS C.E., Patterns of compartment involvement in tibiofemoral osteoarthritis in men and women and in whites and African Americans, Arthritis Care Res., 2012, 64, 847-852. 